\title{
MEMÓRIA E VERDADE NA TRANSIÇÃO DEMOCRÁTICA BRASILEIRA: O EMBLEMÁTICO FILME A FREIRA E A TORTURA (1983), DE OZUALDO CANDEIAS
}

\author{
MEMORY AND TRUTH IN THE BRAZILIAN DEMOCRATIC TRANSITION: \\ THE EMBLEMATIC FILM A FREIRA E A TORTURA (1983), \\ BY OZUALDO CANDEIAS
}

\begin{abstract}
Alcilene Cavalcante Oliveira*
Resumo: Este artigo parte do conceito Justiça de transição, especificamente de seu pilar Memória e Verdade, no contexto de transição democrática no Brasil, para destacar a relevância do cinema nacional quanto à problematização da memória sobre o passado de ditadura civil-militar no país (1964-1985). Analisa-se o filme A freira e a tortura, de Ozualdo Candeias, lançado em 1983, que, ambientado nos anos 1970, mostra a repressão às religiosas em instâncias do Estado de exceção - em que direitos foram suspensos e outros violados. Considera-se que esse longa-metragem, de ficção, integra a produção conflitiva de memórias que se realiza no país, desde o início da abertura política (1974), para enfrentar o passado de ditadura - marcado pela violência perpetrada pelo Estado. Observa-se que a despeito de suas ambiguidades e contradições, o artefato cultural estabelece uma visão menos conciliadora sobre aquele processo político, desvelando, isto sim, o autoritarismo e a violência política do período, inclusive a violência de gênero.
\end{abstract}

Palavras-chave: justiça de transição; memória; religiosas; cinema.

\begin{abstract}
This article is based on the concept of Transitional Justice, specifically its pillar Memory and Truth, in the context of democratic transition in Brazil, in order to highlight the relevance of national cinema to the problematization of memory about the past of civil-military dictatorship in Brazil (1964-1985). In particular, we analyze the film A Freira e a tortura by Ozualdo Candeias, released in 1983, which, set in the 1970s, shows the repression of women religious in the instances of the State of exception, where rights have been suspended and others violated. It is considered that this film, fiction, integrates the conflictive production of memories that takes place in the country, from the beginning of the political opening (1974), to face the past of dictatorship - marked by the violence perpetrated by the State. It is observed that, despite its ambiguities and contradictions, the cultural artifact establishes a less conciliatory vision about that process of dictatorship, revealing, rather, authoritarianism and political violence of the period, including gender violence.
\end{abstract}

Keywords: transition justice; memory; religious; films.

\footnotetext{
* Docente da Faculdade de História, da Universidade Federal de Goiás (UFG), na área de História do Brasil, subárea História do Brasil Contemporâneo. E-mail: alcilenecavalcante@gmail.com.
} 
Memória e verdade na transição democrática brasileira: o emblemático filme a freira e a tortura (1983), de Ozualdo Candeias

\section{INTRODUÇÃO}

Sim, esta memória é perigosa, pois, logo de saída, ela denuncia que o presente se assenta sobre uma montanha de cadáveres e de ruínas. Ela também é perigosa porque expõe aquele que recorda a um novo sofrimento. E, por fim, ela é perigosa, pois reacende uma batalha hermenêutica sobre a significação do passado (SILVA FILHO, 2009, p. 128).

O tema Memória e verdade, em contextos de transições democráticas, inserese em um espectro político mais específico, correspondendo a um dos pilares da justiça de transição. Antes de adentrarmos em tal tema, que implica a "memória perigosa", a que a epígrafe acima tece referências, faz-se necessário assinalar que o conceito justiça de transição ou justiça transicional resultou do encontro entre as ciências política e jurídica, cujos trabalhos nessa chave, desde as últimas décadas do século $\mathrm{XX}$, remetem aos períodos imediatamente posteriores às guerras, aos fascismos, às ditaduras, enfim, às situações políticas supostamente excepcionais (CUEVA, 2001).

De acordo com Ruti Teitel, “[...] a justiça transicional pode ser definida como a concepção de justiça associada aos períodos de mudanças políticas, caracterizadas por respostas legais com o objetivo de enfrentar os crimes cometidos por regimes repressores"1 (TIETE, 2003, p.1). Em outras palavras, trata-se de um conjunto de medidas empreendidas, na perspectiva da democracia liberal, com o propósito de lidar com os desdobramentos da violência política perpetrada pelos regimes autoritários ou pelas situações de guerra, a fim de colaborar com a retomada da paz e da democracia, do Estado de direito e de respeito aos direitos individuais e coletivos (QUINALHA, 2013; TOSI; SILVA, 2014; SILVA; VIEIRA, 2009).

É certo que os movimentos de direitos humanos, o aprimoramento da legislação internacional de direitos humanos e a própria legislação humanitária contribuíram sobremaneira para a estruturação do repertório da justiça de transição, por conseguinte, para que a comunidade internacional passasse a considerar as obrigações dos Estados para com as vítimas daqueles contextos políticos que promoveram violações de direitos (PIOVESAN, 2010). 
Nessa perspectiva, Napolitano assinalou que em processos de redemocratizações, “[...] a reconstrução das instituições democráticas, dos direitos fundamentais dos cidadãos, da tolerância e das relações sociais de convivência tem passado, necessariamente, pelo enfrentamento do legado e dos traumas do passado conflituoso" (NAPOLITANO, 2015, p. 12).

O tema da justiça de transição tem saído da seara dos cientistas sociais, historiadores, atores políticos e alcançado o espaço jurídico latino-americano, nos últimos anos. Tem se relacionado mais diretamente ao debate sobre transições democráticas, para indicar, entre outros aspectos, que "[...] os Estados detenham, investiguem, castiguem, reparem e impeçam futuras violações [dos direitos humanos] em seus territórios" (SILVA; VIEIRA, 2009, p. 237).

Alexandre Garrido Silva e José Ribas Vieira descreveram sete dimensões da justiça de transição para confrontar o passado de violência na região, reconhecer a universalidade dos direitos humanos e reconfigurar o papel do Estado em perspectiva democrática (SILVA; VIEIRA, 2009, p. 237). Nos limites deste artigo, no entanto, destacam-se apenas as quatro dimensões para a Justiça de transição reiteradas, entre outras, na publicação que resultou do VII Seminário Internacional de Direitos Humanos da Universidade Federal da Paraíba (UFPB), em 2012, intitulado Justiça de Transição: direito à justiça, à verdade e à memória, quais sejam:

1) Reconhecimento moral e político oficial das responsabilidades do Estado pelos crimes praticados por agentes públicos, reparação moral e ressarcimento material dos danos sofridos pelas vítimas e pelos familiares.

2) Justiça: punição dos agentes públicos que cometeram crimes durante a ditadura, o que no caso brasileiro implica na reavaliação e reabertura da Lei de (auto)anistia de 1979.

3) Memória e verdade: resgate amplo dos conhecimentos e informações ocultadas durante o período ditatorial.

4) Reforma das instituições perpetradoras de abuso, à promoção da reconciliação, e o fortalecimento das instituições democráticas (TOSI; SILVA, 2014, p. 44-45). ${ }^{2}$

Desses quatro pilares, a literatura sobre a Justiça de transição brasileira assinala que apenas aquele referente à reparação tem sido implementado (Idem). É possível considerar, no entanto, a partir da proposta de trabalho das Comissões da Verdade - instaladas no país a partir de 2012 -, que aspectos significativos relacionados à memória vieram à tona, reunindo material bastante rico para os estudos sobre o período - apesar dos esforços esbarrarem nas dificuldades de promoção do amplo debate na sociedade, previsto no pilar correspondente (ARAÚJO, 2012). 
Memória e verdade na transição democrática brasileira: o emblemático filme a freira e a tortura (1983), de Ozualdo Candeias

O êxito da justiça de transição brasileira tem sido comprometido, inevitavelmente, pelos próprios limites da transição democrática no país (1974-1989), pois, conduzida de maneira lenta, segura e gradual pelos militares, configura-se ainda inconclusa, conforme apurado por diferentes historiadores (FICO, 2012; REIS, 2014). Tanto é assim que, quatro décadas após o início de tal processo, ainda não houve a abertura e acesso a todos os arquivos dos aparatos repressivos da ditadura; não se apurou e responsabilizou os agentes do Estado, que violaram direitos; não se esclareceu os crimes, tampouco localizou e identificou todos os corpos de cidadãos sequestrados por tais agentes. Ao contrário, em tal período político, promoveu-se certa política de esquecimento sobre o passado de violência (RUIZ, 2009; SILVA; VIEIRA, 2009; TELES; SAFATLE, 2010; QUINALHA, 2013; TOSI; SILVA, 2014; BRITO, 2013).

Não é a pretensão detalhar a justiça de transição no Brasil, neste artigo, isto sim, direcionar o olhar para o pilar Memória e verdade, a fim de destacar a relevância do cinema nacional, especialmente do filme A freira e a tortura, de Ozualdo Candeias, para a problematização da memória sobre temas do período de ditadura civil-militar (19641985).

\title{
2. MEMÓRIA E VERDADE
}

O pilar Memória e verdade relaciona-se diretamente ao dever de justiça. De acordo com a perspectiva de Castor Ruiz:

\begin{abstract}
A justiça não se limita à razoabilidade dos argumentos, algo do presente, nem à legitimidade dos procedimentos, próprio da ordem estabelecida. A justiça, embora exija ambos os elementos, existe a partir de sua relação com a alteridade humana, em especial o outro injustiçado, o que a torna eminentemente ética. (...) o passado da barbárie ou da injustiça há de ser lembrado como condição da justiça do presente. Sem a recordação da barbárie passada, das suas vítimas, não há justiça no presente (RUIZ, 2009, p. 8).
\end{abstract}

Enfrentar, pois, o passado de violência política perpetrada pelo Estado, na perspectiva da justiça de transição, requer a recuperação do período por meio de relatos, testemunhos e documentos, ou seja, recuperar a memória perigosa, como define a epígrafe acima. Isso é condição para reconstituir o acontecido e assim procurar superá-lo. Nesses termos, Silva Filho acrescenta que:

Recuperar a memória não significa apenas reforçar a garantia de que as ditaduras e os totalitarismos nunca mais ocorrerão. É mais do que isso. Significa fazer justiça àquelas vítimas que caíram ao longo do caminho. Fazer 
justiça significa dar voz aos emudecidos pela marcha amnésica do progresso; significa resistir à destruição do diverso e do plural sob a desculpa da unidade, seja ela a da soberania nacional, a do desenvolvimento econômico ou a da razão científica (...) (SILVA FILHO, 2009, p. 134).

Recuperar o passado, por meio da memória, seja individual ou coletiva, não significa, pois, apenas defender que aquela violência vivida ou que o Estado autoritário não volte a se instalar; consiste, isto sim, garantir a justiça. Nesse sentido, nos termos da justiça de transição, Marco Antônio Barbosa e Paulo Vanucci destacaram que a memória é relevante também para despertar tal sentimento de justiça e a reconciliação na sociedade. De acordo com suas palavras:

\begin{abstract}
Resgatar a memória, com verdade, permite, ademais, elucidar o que é inconsciente e irracional, trazendo-os para o nível da consciência racional e garantindo um processamento transformador que ao mesmo tempo liberta e condiciona todas as possibilidades de reconciliação (BARBOSA; VANUCCI, 2009, p. 58).
\end{abstract}

Todavia, esse instrumento da justiça foi fragilizado no Brasil, em decorrência do formato da transição democrática no país - conforme assinalado acima. Um dos aspectos legais que serviu para estabelecer esses contornos da transição consistiu na Lei da Anistia, promulgada a 28 de agosto de 1979. Com isso, passou-se a ditar certo caráter de reconciliação, ao garantir “ [...] a impunidade para os militares em troca da reintegração dos cidadãos proscritos na vida política e o retorno do exílio" (BRITO, 2013, p. 237). A anistia adquiriu tal desenho, a despeito do movimento da sociedade civil organizada reivindicar seu caráter amplo, geral e irrestrito.

Com essa tônica de reconciliação descartaram as medidas para o estabelecimento da Memória e da Verdade sobre a última ditadura civil-militar no país. É certo que o esquecimento, os silêncios, os não-ditos fazem parte da memória, podendo “[...] se transformar num precioso aliado no processo de recordação quando o sujeito do lembrar desiste de tudo controlar no campo restrito de sua consciência" (GAGNEBIN, 2010, p. 179). Mas não era esse o esquecimento que estava posto. Ao contrário, por meio da Anistia, o Estado promovia certa política do esquecimento, que, segundo Enrique Padrós, consistia na institucionalização de um silêncio oficial sobre as práticas repressivas, com o propósito de “[...] suprimir, da memória coletiva, as responsabilidades e a vontade de justiça nas vítimas" (PADRÓS, 2001, p.88).

Do mesmo modo, Alexandre Silva e José Ribas Vieira assinalam que, além da permanência de violações sistemáticas aos direitos no Brasil, 
Memória e verdade na transição democrática brasileira: o emblemático filme a freira e a tortura (1983), de Ozualdo Candeias

\begin{abstract}
tivemos ao longo desse período, com a contribuição - por via omissiva - dos principais meios de comunicação de massa, a construção de uma "política do esquecimento" no tocante às pretensões de busca pela verdade, resgate da memória, condenação e reparação dos delitos cometidos por militares e burocratas civis vinculados ao regime autoritário no Brasil. Criou-se assim a ideia de reconciliação como esquecimento e, consequentemente, como impunidade (SILVA; VIEIRA, 2009, p. 235).
\end{abstract}

Glenda Mezarobba, por sua vez, reitera essa chave de leitura ao evidenciar o caráter precário da justiça de transição no Brasil, decorrente da mobilização da “[...] memória do esquecimento que a Lei de Anistia propôs e a legislação subsequente tratou de reiterar" (MEZAROBBA, 2010, p. 115).

Já Alexandra Barahona de Brito reiterou que a justiça de transição no país não partiu do Estado e destacou as iniciativas da sociedade civil para realizá-la (BRITO, 2013, p. 238). Para ela, a primeira iniciativa de empreender o enfrentamento do passado de violência partiu de uma equipe de 30 pessoas - vinculadas ao cardeal Paulo Evaristo Arns, da Arquidiocese de São Paulo, e ao pastor presbiteriano Jaime Wright, do Conselho Mundial das Igrejas - que tinha acesso às instâncias do Estado. Tais pessoas conseguiram fotocopiar “[...] secreta e meticulosamente mais de um milhão de páginas de documentos confidenciais relacionados com o julgamento de 707 "subversivos" pelo Supremo Tribunal Militar (STM)", o que resultou no relatório Brasil Nunca Mais, publicado em 1985 (BRITO, 2013, p. 238).

Os dados reunidos em tal relatório foram complementados, com o tempo. Atualmente, os estudiosos apontam que cerca de 50 mil pessoas foram detidas após o golpe civil-militar, de 1964, sendo que quinhentos foram mortas, das quais 144 pessoas foram "desaparecidas", e milhares de pessoas foram torturadas e privadas dos seus direitos políticos. Cerca de 10 mil foram forçadas ao exílio (BRITO, 2013, p. 238).

A partir da divulgação desses dados, em meados dos anos 1980, algumas medidas pontuais foram adotadas em alguns níveis do Estado, quanto ao passado de violência, mas sempre em razão de contingências sociais e das pressões de familiares das vítimas e de organizações dos direitos humanos. Assim, em 1990, ao se localizar “despretensiosamente" ossadas humanas em valas comuns no cemitério de Perus, em São Paulo, e, ainda, em meio ao contexto internacional de aberturas de arquivos, o então presidente Color de Mello ordenou a transferência dos registros policiais para os governos estaduais. Nessas circunstâncias, alguns governadores de estado aproveitaram para abrir também seus arquivos. Além disso, a então prefeita de São Paulo, Luísa Erundina (PT), 
instituiu uma comissão especial para investigar os restos mortais encontrados naquele cemitério de São Paulo (BRITO, 2013, p. 239). Isso tudo, evidentemente, sob a pressão de organizações de direitos humanos.

Nos anos seguintes, outras iniciativas foram tomadas pelos governos de Fernando Henrique Cardoso, de Luís Inácio Lula da Silva e de Dilma Rousseff, no âmbito da justiça de transição, mas sem alcançar o êxito esperado para se completar o processo no país (BRITO, 2013; QUINALHA, 2013; MEZAROBBA, 2010; SOARES, 2009).

Destaca-se, no entanto, que se o Estado brasileiro, desde a transição democrática (1974-1989), negligenciou ou agiu timidamente no enfrentamento da violência perpetrada durante a ditadura civil-militar, no que se refere, inclusive, à recuperação de memórias, com verdade, sobre o período, já na esfera social, diferentes segmentos movimentaram o mercado editorial e os circuitos cinematográficos brasileiros produzindo memórias sobre aquele período.

Para Barahona de Brito, “[...] a memória é parte da produção cultural que fomenta a criação de biografias, estudos acadêmicos, romances, filmes, produções teatrais gerando uma constante e renovada interpretação do passado" (BRITO, 2002, p. 68). Todavia, a autora observa que: “[...] a política oficial de memória promove a adoção de uma série de comemorações e a construção de determinados monumentos, havendo no interior dessa produção duras batalhas políticas em torno do conteúdo simbólico e do caráter reparador dos ditos fios da memória" (BRITO, 2002, p. 68)³.

Note-se que a produção de memórias está inserida no espectro mais amplo das políticas de memórias, cujas ações desdobram-se em dois níveis: de um lado, considerado mais estrito, localizam-se as políticas elaboradas para enfrentar o passado, que implica a constituição de memórias oficial e pública; de outro, trata de como a sociedade interpreta e se apropria de seu passado (memória social) (BARAHONA, 2006, p. 69).

Para Brito "[...] as memorias históricas e as lembranças coletivas podem configurar instrumentos para legitimar discursos, criar lealdades e justificar opiniões públicas” (BRITO, 2002, p. 69). E ainda: “[...] o que as sociedades elegem recordar ou esquecer e de que maneira o fazem é algo que condiciona, em parte, suas opções futuras" (BRITO, 2002, p. 69) ${ }^{4}$.

Nos anos que se seguiram a abertura política no Brasil houve certa profusão de publicações de relatos, testemunhos, memórias, que construíam certas visões sobre o período de governos civis-militares no país, mas de maneira independente, isto é, 
Memória e verdade na transição democrática brasileira: o emblemático filme a freira e a tortura (1983), de Ozualdo Candeias

desvinculada de um processo formal de justiça de transição e de políticas de memórias.

Sobre esse aspecto, Carlos Fico assinalou que:

as primeiras revelações mais precisas, descrevendo os subterrâneos do regime, provieram das memórias. Há a memória da esquerda, de grande impacto editorial, sobretudo a dos militantes que experimentaram os desacertos da "luta armada" e, derrotados, compuseram pungente narrativa sobre a tortura. Como em contraposição, a memória dos próprios militares, alguns desgostosos por terem sido afastados do poder, outros tentando defender supostas positividades do regime ou pretensas necessidades inexoráveis de repressão (FICO, 2002, p. 251).

Daniel Aarão Reis filho, por sua vez, tece críticas ao traço que marcou essa produção de memórias, do período inicial de abertura política no Brasil. O historiador destacou:

em vez de abrir amplo debate sobre as bases sociais da ditadura, escolheu-se um outro caminho, mais tranquilo e seguro, avaliado politicamente mais eficaz, o de valorizar versões memoriais apaziguadoras onde todos possam encontrar um lugar (REIS, 2014, p. 8).

Ao considerar que o cinema entra nessa produção conflitiva de memórias, às vezes de maneira bastante incisiva, sustenta-se, neste texto, que diferentes filmes da transição democrática brasileira (1974-1989) se inseriram na perspectiva de revisão do passado de ditadura civil-militar - marcado pela violência perpetrada pelo Estado -, estabelecendo uma visão menos conciliadora, isto sim, desvelando o autoritarismo e a violência política do período (CAVALCANTE, 2014).

Parte-se, pois, do pressuposto que filmes são veículos de memórias, produzindo, difundindo discursos sobre o passado e entrando nos embates desse campo (ROUSSO, 2016a; FERRO, 2004). De acordo com as palavras Michel Pollack, um filme configura um suporte de memória, inserindo-se nas disputas e ampliando o debate. Para ele:

Nas lembranças mais próximas, aquelas de que guardamos recordações pessoais, os pontos de referência geralmente são de ordem sensorial: o barulho, os cheiros, as cores... Ainda que seja tecnicamente difícil ou impossível captar todas essas lembranças em objetos de memória confeccionados hoje, o filme é o melhor suporte para fazê-lo: donde seu papel crescente na formação e reorganização, e, portanto, no enquadramento da memória. Ele se dirige não apenas às capacidades cognitivas, mas capta as emoções [...]. $\mathrm{O}$ filmetestemunho e documentário tornou-se um instrumento poderoso para os rearranjos sucessivos da memória coletiva e, através da televisão, da memória nacional (POLLACK, 1989; p. 12).

Henry Rousso, por sua vez, reitera essa perspectiva, ao assinalar que: 
[...] sente-se, claramente, hoje, que, para o senso comum, um filme, uma obra de história, um programa de televisão ou um artigo de jornal podem ter o mesmo escopo pedagógico e que eles podem falar com uma capacidade equivalente sobre o passado (apud FILMER LE PASSÉ, 2008, p. 18).

Ao detalhar essa questão, Claudia Feld e Jessica Stite Mor assinalam que as imagens fílmicas permitem acessar o passado e adentrar no complexo espaço da construção de memórias. Segundo elas:

Em suas complexidades, paradoxos, dilemas éticos e ambiguidades, as imagens revelam-se como poderosos instrumentos não apenas para conhecer o passado e estudar as representações que produzem novas memorias, senão também para tornar inteligíveis os complicados mecanismos da memoria social (FELD, 2009, p. 32)

Desse modo, é no fecundo espaço de produção de memorias, paralelamente às configurações da justiça de transição no Brasil, que se insere o emblemático filme $A$ freira e a tortura, de Ozualdo Candeias, lançado em 1983.

\section{A FREIRA E A TORTURA}

O filme A Freira e a tortura, do cineasta brasileiro Ozualdo Candeias, lançado em 1983, é um longa-metragem, de ficção, cuja produção é de baixo-custo, as imagens são sujas, o elenco é composto de atores amadores, advindos das produções de filmes pornôs, e a linguagem sugere a filiação da trama ao cinema marginal (UCHOA, 2013). Neste estilo, apresenta personagens cujas atitudes humanas aproximam-se do "animalesco" pelo gestual, pelos gemidos, "pela emissão de voz pouco articuladas"; “enfim, por uma série de elementos esculachados", conforme Bernardet apontou como características desse tipo de cinema (BERNARDET, 2004, p. 14) ${ }^{6}$.

Angela Teles, ao pesquisar parte da cinematografia desse diretor, entre 1967 e 1992, destaca que a caracterização dos filmes de Candeias como sendo de estilo marginal seria apenas uma saída fácil para a complexidade do repertório de questões que sua obra enseja, além de o próprio diretor recusar tal rótulo (TELES, 2012, p. 194). A pesquisadora sustenta que o cinema de Candeias se vincula ao que ela denominou "estética da precariedade", isto é: "a construção estética da miséria e da precariedade como luta política" (TELES, 2012, p. 207). Trata-se da construção imagética "da realidade da miséria, da privação e da contingência a partir da perspectiva do migrante 
Memória e verdade na transição democrática brasileira: o emblemático filme a freira e a tortura (1983), de Ozualdo Candeias

pobre" (TELES, 2012, p. 207). Tais traços podem ser verificados também no filme A freira e a tortura, especialmente na ambientação dos espaços pelos quais a protagonista transita e pelos perfis dos personagens com os quais ela interage, como o "deficiente" e a prostituta - aliás, personagens comuns na filmografia do diretor.

O filme desvela a influência da pornochanchada por meio da nudez de personagens, de homens e de mulheres, e de cenas de sexo. Atores considerados ícones das realizações da Boca do lixo e de filmes eróticos, dos anos 1960 e 1970, David Cardoso e Vera Gimenez, interpretam, respectivamente, o delegado Daniel, o algoz, e, a freira Joana - protagonistas dessa trama de Candeias ${ }^{7}$.

Realizado e exibido no início dos anos 1980, em São Paulo, período de transição democrática brasileira, o filme mostra a prisão arbitrária e a tortura de uma freira em cadeias clandestinas, controladas pelos agentes do Estado, sob o comando do suposto delegado Daniel. A trama adquire relevância tanto ao encenar a violência perpetrada pelo Estado, durante a ditadura civil-militar no Brasil, como por levar para a tela a violência específica contra uma religiosa. Trata-se de um tema raro nas cinematografias latinoamericanas do período e ainda incipiente na historiografia brasileira (CUBAS, 2015, p. 140).

A freira e a tortura engendra a memória daquele período de repressão, ao exibir sequências ficcionais de arbitrariedade e de torturas, inclusive problematizando a violência de gênero ${ }^{8}$. Para compreender a relevância desse aspecto da representação fílmica, faz-se necessário abrir uma nota sobre a violência empreendida durante a ditadura, cujas tipificações alteraram-se ao longo do tempo.

Os estudos sobre a violência praticada pelos agentes da ditadura consideravam, até a bem pouco tempo, que a repressão, especialmente a tortura, havia sido semelhante para homens e mulheres (JOFFILY, 2009). Isso se depreendia, inclusive, de processos judiciais produzidos durante a ditadura civil-militar brasileira, reunidos na referida publicação Brasil Nunca mais. Tal indistinção residia na relação que se estabelecia entre a ditadura e contextos de guerra, em que era comum ocorrer certa “confusão na fronteira de gênero" (JOFFILY, 2009, p. 83).

Todavia, com o desenvolvimento dos estudos feministas e de gênero, especificamente, com a aplicação da categoria gênero às análises, já a partir da segunda metade dos anos 1980, tem sido possível constatar que a repressão acarretava impacto diferente para homens e mulheres, em função do modelo de gênero vigente, que 
implicava, entre outros aspectos, a subordinação das mulheres aos homens (VEIGA; PEDRO, 2015). Nesse sentido, Mariana Joffily destacou:

O fato da quase totalidade dos torturadores serem do sexo masculino, ao mesmo tempo em que demonstra a vigência de um sistema de gênero bastante desigual, significa que as mulheres vítimas da violência política estavam em situação desfavorável, pois a própria situação de estar despida diante de um homem constituía uma humilhação considerável (JOFFILY, 2009, p. 85).

Tratava-se de um sistema de repressão, no qual os agentes da tortura eram compostos quase que exclusivamente de contingentes masculinos. Homens que torturavam homens e mulheres, sendo que a nudez, a que era submetida os detidos políticos, exprimia significados diferentes para homens e para mulheres.

A referida historiadora considerou ainda a diferença entre a violência sexual e o abuso sexual, reiterando os testemunhos e as análises que apuraram que homens foram violados sexualmente assim como as mulheres, só que acentuadamente em menor número. Ela sublinhou que o abuso, que remete ao prazer sexual, voltou-se especificamente contra as mulheres. E acrescentou que as torturas psicológicas, implicando os temas da maternidade e da família, de um modo geral, eram dirigidas e afetavam mais diretamente às mulheres, ao se considerar os papeis sociais hegemônicos de gênero (JOFFILY, 2009, p. 82).

Essa questão de gênero passou então a fazer parte do repertório da justiça de transição. Tanto é assim que Silva e Vieira acrescentaram aos quatro pilares desse sistema de justiça a observância da dimensão de gênero. Segundo suas palavras: é necessária a “[...] consideração da questão de gênero com o objetivo de melhorar a justiça para as mulheres que foram vítimas de violações dos direitos humanos" (SILVA; VIEIRA, 2009, p. 238).

Outro aspecto que é importante salientar, na chave das conexões entre o filme e os apontamentos da literatura sobre o passado recente de ditadura, refere-se ao fato de o longa-metragem em questão, de Ozualdo Candeias, ter se baseado na peça de teatro Milagre na Cela, de Jorge Andrade, datada de 1977. Sem adentrar no exercício de cotejamento e de análise intertextual das obras teatral e fílmica, assinala-se apenas que os principais elementos dramáticos da peça localizam-se no filme (ARANTES, 2009, p. 81). Acrescente-se que a peça foi censurada, em agosto de 1977, não sendo montada, mas obteve uma leitura dramática no Rio de Janeiro, em outubro do mesmo ano, sendo que a 
Memória e verdade na transição democrática brasileira: o emblemático filme a freira e a tortura (1983), de Ozualdo Candeias

sua publicação em formato de livro rendeu diferentes matérias em periódicos de circulação nacional, naquele final dos anos 1970.

Em diferentes matérias, o dramaturgo Jorge Andrade revelou que construiu a protagonista de sua peça a partir de casos verídicos, conforme destacado no trecho: “(...) Milagre na cela trata do relacionamento entre torturador e torturada e foi baseada em fato real - uma freira e duas educadoras - que foram torturadas pelo delegado Fleury. Juntei os três casos em um só, criando a personagem da freira madre Joana de Jesus Crucificado" (Jornal do Brasil, 1977).

O filme de Candeias, que também fora censurado, sendo impedido de ser exibido no Festival de Cinema de Brasília, em 1983 - um sinal da permanência da censura na transição democrática -, inspirou-se em fatos reais para encenar a prisão e a tortura de uma religiosa ${ }^{9}$.

\subsection{Um olhar sobre sequências do filme}

O enredo do filme, em síntese, consiste na prisão de uma freira que realizava trabalho de alfabetização em uma favela de São Paulo, entre 1960 e 1970, indicando já de início a construção de uma personagem relacionada a certo segmento da igreja católica, comprometido com mudanças sociais no Brasil ${ }^{10}$. O agente do Estado ditatorial que efetuou a prisão, o delegado Daniel, acompanhado de dois homens sob o seu comando, é tratado como doutor pelos demais agentes e como colega pelo delegado responsável pela instituição policial, para onde a religiosa fora levada.

As diferentes sequências do filme encenam os bastidores das instituições repressivas do Estado, desvelando práticas de violência. Nelas, o delegado Daniel utilizase de diferentes tipos de tortura para obter depoimento da religiosa, que é suspeita de colaborar com militantes de esquerda. Desde a primeira cena, no entanto, o movimento de câmera constrói certa atmosfera de "sedução" entre a torturada e o algoz, por meio do enquadrando de determinados gestos, olhares e pela marcação do áudio: entonação dos personagens ${ }^{11}$.

A prisão da freira é realizada de maneira arbitrária, seguida de um sequestro, pois ela teve direitos básicos suspensos, inclusive sendo impedida de se comunicar com qualquer pessoa, mesmo integrantes de sua congregação religiosa e da família. É submetida repetidamente, desde o primeiro momento, aos assédios moral e sexual.

Torturas psicológicas e físicas perpassam a trama, são mostradas em tela, guardando para o desfecho o abuso sexual. Mas a religiosa, que protagoniza a trama, não 
se rende. Ao contrário, além de resistir, ela desafia o torturador questionando-o a ponto de desconsertá-lo. Ele, por sua vez, também não desiste: empreende diferentes maneiras de torturar com o propósito de fazer Joana dar alguma informação sobre grupos de esquerda.

Em outra sequência, após muitas ameaças, empurrões, apertões e outros tipos de violências encenadas, a freira é transferida para outro lugar, um cativeiro da repressão. Nessa cadeia clandestina, o delegado-torturador, que já fora mostrado, em outra cena, como um homem comum - casado e dedicado à esposa e ao filho -, lentamente, tira o casaco, coloca as armas sobre uma mesa, desabotoa a camisa e a calça. Ao mesmo tempo, pergunta para a freira: “Já viu homem pelado?" O algoz busca, em tal cena, a cumplicidade da protagonista, fazendo outra pergunta: "você sabe o que estou fazendo, não?”.

A freira demonstra constrangimento, desviando o olhar. O delegado puxa-a para perto de si e faz com que ela olhe para o seu órgão genital. Antes, contudo, ele dá sinais de que não havia ereção, e diz: "olha, o nome do apito chama anjo, porra. Se bem que hoje ele está a fim de me dar vexame". Ao segurar o pênis, acrescenta: "se bem que ele não é assim, não. Ele é daqueles que cresce na mão. Ele fica grande, fica grande mesmo".

Esse comportamento do delegado-torturador configura, certamente, abuso sexual, mas a sequência revela ainda certo deboche ao mostrá-lo sem ereção, o que, além de reiterar certo topos de masculinidade, subverte as comédias eróticas do período ${ }^{12}$.

De volta à delegacia, a religiosa passa por duas outras tentativas de abuso sexual: na primeira, é colocada na cela onde se encontrava uma prostituta, que é caracterizada como compulsiva sexual. O delegado-torturador manda o carcereiro persuadir a prostituta detida para abordar sexualmente a freira, a fim de obter informação sobre militantes políticos.

A prostituta, de maneira invasiva circula em torno da freira, examinando seu corpo. A freira, sem esmorecer, toma a mulher pelo braço e tenta aproximar-se dela de maneira amistosa, dissuadindo-a de seu propósito inicial. Em seguida, o carcereiro aparece em quadro indagando a prostituta sobre se ela havia dado um "trato na freira", ao que ela respondeu: "Que trato que nada. Primeiro, nem gosto de mulher; depois, nem sou da religião dela...”.

Em nova tentativa de dobrar a freira, o delegado-torturador colocou um homem, já mostrado como compulsivo sexual, na mesma cela em que a religiosa se R. Fac. Dir. UFG, v. 41, n. 3, p.138-159, set/dez. 2017 
Memória e verdade na transição democrática brasileira: o emblemático filme a freira e a tortura (1983), de Ozualdo Candeias

encontrava, com o propósito de violentá-la, sugerindo que o estupro configurava instrumento de persuasão e de poder policial. Tudo em vão: a freira não apenas escapou da violência do maníaco, como o tornou seu aliado, por meio de um diálogo freudiano de ausência e de projeção materna.

Em outra sequência, a freira ocupa o quadro, encontrando-se despida e com as mãos algemadas por trás do corpo. Em quadro, aparece um dos agentes da repressão que pega o cassetete de borracha e, ao aproximar-se da religiosa, ameaça introduzi-lo na vagina dela. Ao mesmo tempo, diz: "acho que agora você vai falar. Se não falar, vou tirar a tua virgindade". Na mesma cena, outro agente entra em quadro, pega outro cassetete e encosta nas nádegas da freira Joana. O delegado-torturador que observava tudo a certa distância, desloca-se até os personagens e toma os instrumentos, jogando-os no chão e leva Joana para outro lado da sala. Os dois homens se entreolham e um deles comenta: “acho que o chefe tá a fim da mulher".

O envolvimento erótico-afetivo entre a vítima e o algoz é desenvolvido na trama. Trata-se de um aspecto que, conforme mencionado acima, não há referência na historiografia brasileira, apenas na argentina. Embora o tema escape ao propósito deste artigo, é importante assinalar que esse tema foi encenado anteriormente em Portier de nuit (1974), da cineasta italiana Liliana Cavani.

Para Foucault, esse tipo de filme insere-se em um verdadeiro combate pela memória, ao recodificar o que ele denominou, em 1974, "memória popular" (FOUCAULT, 2006). Tratava-se de um momento, em que o cinema e a televisão recodificavam a memória de pessoas que "não têm o direito à escrita, de fazer elas próprias seus livros, de redigir sua própria história" (FOUCAULT, 2006, p. 332). O autor acrescenta, como aspecto positivo, o fato de filmes como Portier de nuit explorarem a estreita relação que há entre o desejo e as relações de poder, o que seria, segundo ele, uma das explicações para a adesão social ao nazismo, por exemplo. Mas, salientou, como aspecto negativo, que a encenação da relação entre erotismo e poder, por meio do envolvimento erótico entre algozes e vítimas, visava apagar a ideia de que houve heróis, por conseguinte, anti-heróis, no contexto encenado, o que resultava na ideia de que não teria havido luta no passado (FOUCAULT, 2006, p. 333).

$\mathrm{Na}$ chave da cultura de massa, Henri Rousso destaca que há certo "fascínio pela violência do século, e até uma forma de voyeurismo que se exprime abertamente durante a tendência dita "retro", com o sucesso ambíguo de um filme como Portier de 
nuit" (ROUSSO, 2016b, p. 198). Esse historiador afirma, ainda, que esse fenômeno ampliou-se nas décadas seguintes do século XX.

É certo que o filme de Candeias encena a incômoda relação erótica entre a Freira e o delegado. Contudo, sobressai a arbitrariedade, a tortura e a assimetria de poder, o que evidencia que o longa-metragem engendra certa memória da violência política empreendida nas instâncias do Estado brasileiro, durante a ditadura civil-militar, mais especificamente a violência de gênero inscrita nas práticas de tortura daquele regime.

\subsection{Outro caso emblemático: a freira Maurina Borges}

Se a trajetória da madre Maurina Borges da Silveira corresponde a uma das três personagens que inspiraram a peça de Jorge Andrade, na qual se baseou o filme de Ozualdo Candeias, não é possível afirmar. Todavia, o caso dessa freira torna-se emblemático, em meio ao silêncio historiográfico brasileiro sobre a repressão às religiosas que se inseriram em causas sociais, caindo nas garras do Estado de exceção, isto é, do Estado autoritário, de suspensão das liberdades individuais (AGAMBEN, $2004)^{13}$.

Maurina Borges dirigia o Lar Santana, um orfanato para meninas, situado em Ribeirão Preto, no interior de São Paulo, quando foi presa, em 25 de outubro de 1969, sob a acusação de acobertar militantes de esquerda, que se reuniam e imprimiam material considerado subversivo, à época, no porão do orfanato.

Em 1970, depois de muitas sessões de tortura, a madre entrou na lista dos militantes de esquerda que foram banidos, exilando-se no México, ao serem trocados pelo cônsul japonês, Nobuo Okushi - sequestrado em São Paulo por militantes da Vanguarda Popular Revolucionária. A religiosa voltou ao Brasil apenas em 1985 e faleceu em 2011.

Sobre a trajetória dessa freira há apenas dois livros de ficção e o relato da enfermeira Áurea Moretti, com quem dividiu cela, no interior de São Paulo (LEONE, 1998; ASSIS, 2013). Somente nos últimos anos, sua trajetória tem configurado objeto de pesquisas acadêmicas, voltadas ao período de ditadura civil-militar no Brasil, que reúnem novos documentos (CUBAS, 2015).

A carta que a freira escreveu para o ministro da justiça Alfredo Buzaid, em dezembro de 1969, quando se encontrava presa no Brasil, desvela certas aproximações com a trajetória ficcional de Joana e de tantas outras pessoas presas arbitrariamente durante o regime civil-militar. Apesar de longo, vale conferir tais aproximações no trecho que segue: 
Fui conduzida ao Quartel Militar de Ribeirão Preto, às 14h do dia 25 de outubro, julgando que se tratasse apenas de uma declaração. Depois de quase meia hora de espera, começaram os interrogatórios, a respeito do movimento. Oito ou mais agentes da Polícia, a paisana, rodearam-me. Comecei logo a falar sobre o que sabia do movimento de juventude existente em minha casa, pois ignorava o tão falado terrorismo. Foi através dos elementos que me interrogavam, que aprendi o que era terrorismo. Não me foi possível continuar, pois interrompiam-me a cada instante, com gritarias e ameaças, usando uma terminologia, a qual sinto-me envergonhada de repeti-la:

"Você sabe que usamos de torturas, mas para você não é difícil suportar, porque a vida das freiras já é uma tortura. É tão cínica, como pode se fazer de inocente, sua freira do diabo. Você não é filha de Deus. Fica sabendo que teremos o prazer de prender bispos e padres, não pense você que eles poderão te livrar. O que você tem nos joelhos, cicatrizes de tanto rezar... e por que não reza agora? Não adianta mais...Você não é mais virgem. Vamos fazer um exame ginecológico. Jogou o hábito fora, ótimo. Podemos fazer de você o que nós queremos..."Davam risadas sarcásticas. Até aquele momento silenciei, escutando tudo aquilo, sem compreender o seu significado.

Em seguida, Dr. Fleury perguntou-me: "Você é amante do Mario Lorenzato? Responda

afirmativo, é o suficiente, estará tudo resolvido. Vai me dizer que é diferente dos outros." Jamais poderia afirmar uma tal mentira. Insistiu muito nisso. Foi então que ligaram a máquina de choques, e se divertiram as minhas custas.

(...) Como religiosa, acostumada a uma vida organizada, em ambiente de respeito, muito me custou suportar, das $19 \mathrm{~h}$ até muito tarde da noite, de um lado os soldados repetindo termos grosseiros, insultos de baixo calão (os quais acho indignos de serem colocados aqui) e, do outro localizava-se a famosa sala de interrogatórios, onde, continuamente, ouviam-se os gritos lancinantes de rapazes torturados e os barulhos de espancamentos; causava-me ainda maior pavor o tintilhar de chaves que abriam as portas a fim de conduzir, a qualquer momento, uma de nós para novos interrogatórios. Assim foi que, depois de meia-noite, fui sobressaltada com o chamado para novo interrogatório. Fui levada à presença de uma pessoa meio loira, de olhos azuis, estatura média, não posso precisar bem (disseram que era um sargento). Perguntei o seu nome a um dos rapazes e a resposta que obtive foi: "NÃO INTERESSA, É UM DOUTOR". Eles se chamavam de "doutores", vestiam-se à paisana e usavam apelidos, suponho que para fugirem à identificação diante das pessoas a quem torturavam. O referido senhor loiro entregando um revolver ordenou que eu o matasse se ele não fosse católico. Como estivesse meio bêbado, sentia-se o repugnante cheiro de álcool. Senti pavor de ficar em sua presença, mas tive de ficar com ele ali, fechada naquela sala, pela noite adentro, atormentada com suas provocações.

Entre outras coisas dizia: "Irmã querida, posso te chamar de irmã, não é? Eu te quero muito. Vem pertinho de mim. Pelo amor de Deus, fala tudo. Eu quero te dar uma "colher de chá", ou melhor, dá-me uma colher de chá. Eu tenho pena de deixar-te nua na presença de todos. É chato pra mim. Vamos, me dá uma colher de chá... pensa bem, eu estou há dias longe da minha mulher..."Enquanto dizia tudo isto abraçava-me, tentava esfregar suas mãos nas minhas e procurava tocar nos meus joelhos. Eu sentia uma repugnância terrível e não via o momento de livrar-me daquele homem. (...) Domingo à noite fui conduzida para a cadeia de Cravinhos, onde permaneci 25 dias incomunicável. Apesar da insistência de meus irmãos vindos de Goiás e Minas Gerais, para obterem notícias minhas, não permitiram que nos comunicássemos. Nem tão pouco foi permitido a minha Superiora Provincial, falar comigo ou mesmo localizar meu paradeiro. Tive a impressão de estar abandonada por todos: pela minha família de sangue e família religiosa, a qual pertenço a mais de 20 anos. Outro tormento foi a falta de assistência religiosa. Por duas vezes solicitei a presença de um sacerdote para levar-me o sacramento da Eucaristia. Não o permitiram dizendo: "TAMBÉM ISTO FAZ PARTE DO CASTIGO". Somente no dia 18 
de novembro, depois de muita insistência, permitiram que, por 10 minutos, na presença de QUATRO policiais, eu pudesse falar com meu irmão.

Dias depois pude ver a madre Provincial, por alguns minutos, também sob a vigilância de

policiais. Conduzida a Ribeirão Preto a fim de prestar depoimento, sendo interrogada por Dr. LAMANO, um dos delegados regionais, tratou-me grosseiramente dando-me pancadas no rosto querendo forçar-me a dizer o que eu não havia feito. Não me foi possível esclarecer nada; tudo era feito na base da gritaria e pancadas naquele interrogatório. A certa altura o referido delegado gritou: "Veja se não vai esquecer do seu Deus?" Agora vai apanhar junto com o rapaz seu protegido." Trazendo o rapaz a minha presença, o delegado intercalava às perguntas, pancadas no moço e em mim. Eram tapas no rosto que me deixavam completamente surda (Apud CUBAS, 2014, p. 271-272).

Note-se que a carta menciona a arbitrariedade da prisão, a tortura, a violência de gênero e a vulnerabilidade da detida, que se tornou presa dos arroubos de agentes do Estado. Trata-se de uma situação de suspensão completa dos direitos, mostrada também no filme de Candeias, e que ilustra em parte o que milhares de pessoas viveram no Brasil durante aqueles anos de ditadura.

\section{CONCLUSÃO}

O Estado brasileiro não conseguiu completar a justiça de transição no país, não dando conta sequer de um de seus pilares, a Memória e a Verdade. Contudo, no âmbito da cultura, diferentes segmentos sociais têm produzido artefatos de memórias, que não deixam esquecer o passado de violência.

Dezenas de filmes brasileiros, além daquele de Candeias abordado neste texto, revisaram e continuam revisando tal passado. Mesmo dos lugares mais inusitados, como a Boca do lixo, surgem representações sobre as barbaridades perpetradas no âmbito do Estado brasileiro, durante a ditadura civil-militar, inclusive, relativas à violência de gênero.

Essa produção de memórias, realizada desde a abertura política, reitera que a imposição do esquecimento, como aquela ditada pela Lei de Anistia, de 1979, nunca nega ou apaga completamente o passado. Nas palavras de Jeanne Marie Gagnebin:

\footnotetext{
A imposição do esquecimento como gesto forçado de apagar e de ignorar, de fazer como se não houvesse havido tal crime, tal dor, tal trauma, tal ferida no passado, esse gesto vai justamente na direção oposta dessas funções positivas do esquecer para a vida. (...)[constitui] uma "memória impedida" [une memoire empêchée], diz Ricoeur, uma memória que vai lutar, brigar para poder voltar (GAGNEBIN, 2010, p. 179).
} 
Memória e verdade na transição democrática brasileira: o emblemático filme a freira e a tortura (1983), de Ozualdo Candeias

A Freira e a tortura, de Ozualdo Candeias, trouxe de volta o tema da repressão às mulheres brasileiras, especialmente às religiosas, como, por exemplo, a madre Maurina Borges, naqueles anos de Estado de exceção, marcados pela suspensão e violação de direitos.

\section{BIBLIOGRAFIA}

AGAMBEN, Giorgio. Estado de exceção. São Paulo: Boitempo, 2004.

ANDRADE, Jorge. Milagre na Cela. Rio de Janeiro: Paz e Terra, 1977.

ARANTES, Luis Humberto Martins. Entre o texto e a tela: apontamentos acerca de Milagre na cela de Jorge Andrade e A freira e a tortura de Ozualdo Candeias. Revista Ouvirouver, $n^{\circ}$ 5, pp. 77-83, 2009.

ARAÚJO, Maria Paula. Comissões de verdade: um debate ético-político na contemporaneidade. In: FICO, Calos; ARAUJO, Maria Paula; GRIN, Monica (orgs). Violência na História: memória, trauma e reparação. Rio de Janeiro: Ponteio, 2012, pp. 145-162.

ASSIS, Denise. Imaculada. Rio de Janeiro: Topbooks, 2013.

BARBOSA, Marco Antonio R.; VANNUCHI, Paulo. Resgate da memória e da verdade: um direito de todos. In: SOARES, Inês Virginia; KISHI, Sandra. Memória e verdade: a justiça de transição no Estado democrático brasileiro. Belo Horizonte: Forum, 2009.

BERNARDET, JEAN-CLAUDE. Cinema marginal? In: PUPPO, Eugênio (org.) Cinema marginal brasileiro: filmes produzidos nos anos 60 e 70. s/L: Heco produções, 2004, pp. 12- 16.

BRITO, Alexandra Barahona de; FERNANDEZ, Paloma Aguilar; ENRIQUEZ, Carmen Gonzalez (eds). Introducción. In:

Las políticas hacia el pasado: juicios, depuraciones, perdón y olvido en las nuevas democracias. Madrid: Ediciones Istmo, 2002. pp. 29-70.

"Justiça transicional" em câmera lenta: o caso do Brasil. In: PINTO, António; MARTINHO, Francisco Carlos Palomanes (orgs). O pasado que não passa: a sombra das ditaduras na Europa do Sul e na América Latina. Rio de Janeiro: Civilização Brasileira, 2013, pp. 235-260.

CAVALCANTE, Alcilene. A representação do passado nas telas: os discursos históricos em filmes de Bemberg e Yamasaki. In: AMANCIO, Tonico (org.). Argentina-Brasil no cinema: diálogos. Niterói: Editora da UFF, 2014, pp. 57-77.

CALVEIRO, Pilar. Poder e desaparecimento: os campos de concentração na Argentina. São Paulo: Boitempo, 2013. 
CUBAS, Caroline. Freiras em movimentos de resistência às ditaduras militares na América Latina. Revista Eletrônica da ANPHLAC, nº. 18, p. 139-161, jan./jul. 2015.

Do hábito ao ato: vida religiosa feminina ativa no Brasil (1960-1985). Tese de doutorado apresentada ao PPG em História da UFSC, 2014.

CUEVA, Eduardo González. Perspectivas teóricas sobre la justicia transicional. In: Seminario "Peru 1980-2000: El reto de la verdad y la justicia" Lima: Asociación Pro Derechos Humanos y la Coordinadora Nacional de Derechos Humanos, 2001.

DELGADO, Lucília Neves. Catolicismo: direitos sociais e direitos humanos (19601970). In: FERREIRA, Jorge; DELGADO, Lucília (orgs). O tempo da ditadura: regime militar e movimentos sociais em fins do século XX. Rio de Janeiro: Civilização Brasileira, 2007, pp. 93-132 (O Brasil Republicano 4).

FICO, Carlos. Prezada Censura: cartas ao regime militar. TOPOI - Revista de História, Rio de Janeiro, v. 5, p. 251-286, 2002.

Versões e controvérsias sobre 1964 e a ditadura militar. In: Revista Brasileira de História. São Paulo, v.24, n.47, p.29-60, 2004.

; ARAUJO, Maria Paula; GRIN, Monica (orgs). Violência na História: memória, trauma e reparação. Rio de Janeiro: Ponteio, 2012. pp. 25-38.

FILMER LE PASSE: Les traces et la mémoire; No pasaran! Albulll souvenir. Paris, L' Harmattan, 2003.

FOUCAULT, Michel. Estética: literature e pintura, música e cinema. Rio de Janeiro: Forense Universitária, 2006 (Ditos e escritos: III).

GAGNEBIN, Jeanne Marie. O preço de uma reconciliação extorquida. In: TELES, Edson; SAFATLE, Vladimir (orgs). O que resta da ditadura: a exceção brasileira. São Paulo: Boitempo, 2010, pp. 177-186.

JOFFILY, Mariana. A diferença na igualdade: gênero e repressão política nas ditaduras militares do Brasil e da Argentina. Dossiê gênero, feminismo e ditaduras, Ano X, n. 21, pp. 78-88, 2. Semestre 2009.

LEONE, Matilde. Sombras da repressão: o outono de Maurina Borges. Petrópolis: Ed Vozes, 1998.

MEZAROBBA, Glenda. O processo de acerto de contas e a lógica do arbítrio. In: TELES, Edson; SAFATLE, Vladimir (orgs). O que resta da ditadura: a exceção brasileira. São Paulo: Boitempo, 2010, pp. 109-122.

NAPOLITANO, Marcos. Recordar é vencer: as dinâmicas e vicissitudes da construção da memória sobre o regime militar brasileiro. Antíteses, Londrina, v. 8, n. 15esp., p. 0944, nov. 2015. 
Memória e verdade na transição democrática brasileira: o emblemático filme a freira e a tortura (1983), de Ozualdo Candeias

PADRÓS, Enrique Serra. Usos da Memória e do Esquecimento na História. Letras, Santa Maria, $\mathrm{n}^{\circ} 22$, jan/jun., pp.79-85, 2001.

PIOVESAN, Flávia. Direito internacional dos direitos humanos e lei de anistia. In: TELES, Edson; SAFATLE, Vladimir (orgs). $O$ que resta da ditadura: a exceção brasileira. São Paulo: Boitempo, 2010, pp. 91-108.

POLLACK, Michael. Memória, esquecimento e silencio. In: Estudos Históricos, Rio de Janeiro, vol 2. no 3, pp. 3-15, 1989.

QUINALHA, Renan. Justiça de transição: contornos do conceito. São Paulo: Expressão popular, 2013.

PEDRO, Joana Maria; VEIGA, Ana. Gênero. In: COLLING, Ana; TEDESCHI, Losandro. Dicionário crítico de gênero. Dourados, MS: Ed. UFGD, 2015, pp. 304-308.

REIS FILHO, Daniel Aarão. Ditadura e democracia no Brasil: do golpe de 1964 à Constituição de 1988. Rio de Janeiro: Zahar, 2014.

ROUSSO, Henry. Face au passé: essais sur la mémoire contemporaine. Paris, Belin, 2016a.

A última catástrofe: a história, o presente, o contemporâneo. Trad. Fernando Coelho, Fabrício Coelho. Rio de Janeiro: FGV Editorial, 2016 b.

RUIZ, Castor Bartomé. Introdução. In: (org.) Justiça e memória: para uma crítica ética da violência. São Leopoldo/RS: Editora da Unisinos, 2009, pp. 7-16.

SECRETARIA ESPECIAL DE DIREITOS HUMANOS. Presidência da República. Direito à Memória e à Verdade. Disponível em http://www1.direitoshumanos.gov.br/mortosedesap/id_livro. Acessado em: 21 Dez. 2011.

SAFFIOTI, Heleieth. Gênero, patriarcado, violência. São Paulo: Editora da Fund. Perseu Abramo, 2004.

SILVA, Alexandre G.; VIEIRA, José Ribas. Justiça transicional, direitos humanos e a seletividade do ativismo judicial no Brasil. Revista Anistia Política e Justiça de Transição/Ministério da Justiça, $\mathrm{n}^{\mathbf{o}}$ 2, jul/dez, pp. 234-267, Brasília: Ministério da Justiça, 2009.

SILVA FILHO, José Carlos Moreira. O anjo da história e a memória das vítimas: o caso da ditadura militar no Brasil. In: RUIZ, Castor Bartomé (org). Justiça e memória: para uma crítica ética da violência. São Leopoldo/RS: Editora da Unisinos, 2009, pp. 121158.

TOSI, Giuseppe; SILVA, Jair Pessoa de Albuquerque. A justiça de transição no Brasil e o processo de democratização in: Justiça de transição: direito à justiça, à memória e à verdade. João Pessoa: Editora da UFPB, 2014, pp. 41-62. 
TEITEL, Ruti. Transitional Justice Genealogy. Harvard Human Rights Journal, Cambridge, MA, vol. 16, pp. 69-94, 2003.

TELES, Angela. Ozualdo Candeias na boca do lixo: a estética da precariedade no cinema paulista. São Carlos: Educ: FAPESP, 2012.

UCHOA, Fábio. Perambulação, silêncio e erotismo nos filmes de Ozualdo Candeias (1967-1983). Tese de doutorado apresentada ao PPG em Ciências da Comunicação da Escola de Comunicações e Artes da USP, 2013.

WORNAT, Olga; LEWIN, Mirian. Putas y guerrilleras. Buenos Aires: Planeta, 2014.

\section{FILMOGRAFIA}

A Freira e a tortura (1983), de Ozualdo Candeia.

Portier de nuit (1974), de Liliana Cavani.

Artigo recebido em 28 de maio de 2017 e aceito em 09 de dezembro de 2017

\footnotetext{
${ }^{1}$ Transitional justice can be defined as the conception of the justice associated with periods of political charge, characterized by legal responses to confront the wrong-doings of repressive predecessor (TEITEL, 2003, p. 69).

${ }^{2}$ Esse seminário foi promovido conjuntamente por diferentes núcleos de estudos e pesquisa da referida universidade, como pela Comissão de Anistia, do Ministério da Justiça do Brasil, e pela Cátedra UNESCO de "Direitos humanos e violência: governo e governança", coordenada na ocasião pela Universidade Externado da Colômbia.
}

${ }^{3}$ La memoria es parte integrante de la producción cultural y da origen a biografías, estudios académicos, novelas, películas, producciones teatrales, generando una constante y renovada reinterpretación del pasado. La política oficial respecto a la memoria impulsa la adopción de una serie de conmemoraciones y la construcción de determinados monumentos; en dicho ambito se libran duras batallas políticas en torno al contenido simbólico y al carácter reparador de dichos "hitos de la memoria" (BRITO, 2002, p. 68).

${ }^{4}$ (...) las memorias históricas y los recuerdos colectivos pueden ser instrumentos para legitimar discursos, crear lealdades y justificar opiniones políticas. E ainda: "Lo que las sociedades eligen recordar y olvidar y de qué forma es algo que condiciona, en parte, sus opciones futuras (BRITO, 2002, p. 69).

${ }^{5}$ (...) permiten un acceso complejo al pasado y a la actividad de construcción de memorias"; En sus complejidades, paradojas, dilemas éticos y ambigüedades, las imágenes se revelan como poderosos instrumentos no solo para conocer el pasado y estudiar representaciones que generan 
Memória e verdade na transição democrática brasileira: o emblemático filme a freira e a tortura (1983), de Ozualdo Candeias

nuevas memorias, sino también para hacer inteligibles los complicados mecanismos de la memoria social (FELD, 2012, p. 32)

6 Ozualdo Candeias (1922-2006) cresceu em São José do Rio Preto/São Paulo. Tornou-se fazendeiro e motorista de caminhão. Nos anos 1950, embora tenha lhe marcado a parceria com José Mojica, aproximou-se das produtoras da Boca do lixo, exercendo diferentes funções em dezenas de filmes realizados naquela região, configurando um dos expoentes do cinema da Boca (STERNHRIN, 2005, p. 83; ARANTES, 2009, p. 83). Sua cinematografia é relativamente extensa: fez inúmeros curtas e longas-metragens. Para destacar apenas alguns longas-metragens, é possível citar: A margem (1967), que permite a crítica vincular o diretor efetivamente ao Cinema Marginal e, ainda: Meu nome é Tonho (1969); A herança (1971); A Freira e a tortura (1983); As belas da Billing (1987); O vigilante (1992/93).

${ }^{7}$ Para uma análise dessa influência bem como da peculiaridade do filme de Candeias relativa ao erótico, ver UCHOA, 2013.

${ }^{8}$ A violência de gênero configura um conceito abrangente, utilizado, às vezes, como sinônimos de violência contra as mulheres e de violência doméstica. Remete, entretanto, às relações interpessoais hierarquizadas, nas quais se verificam assimetrias de poder, implicando relações de dominação, marcadas pela desigualdade entre homens e mulheres (SAFFIOTI, 2004). Sobre o conceito gênero, ver: PEDRO; VEIGA, 2015.

${ }^{9}$ Se a pesquisa que realizamos sobre as cinematografias brasileiras, de ficção, do período de transição democrática no Brasil, levou-nos a indagar, a partir do filme A Freira e a Tortura, se havia casos de prisão e tortura de religiosas, o parênteses que abrimos para rastrear a dramaturgia de Jorge Andrade, permitiu-nos localizar o lastro com a realidade social e nos dirigir para identificar a religiosa mencionada.

${ }^{10}$ Lucília de Almeida Neves Delgado aponta que a repressão aos religiosos durante a ditadura deve ser entendida no contexto da orientação da igreja católica para a justiça social - delineada tanto no Concílio do Vaticano II (1962-1965), quanto na II Conferência Geral do Episcopado Latino-Americano, em Medellín (1968). A partir desses eventos, segundo a historiadora, "um novo olhar" conduziu a ação de católicos, havendo a "(...) necessidade de uma renovação eclesial e a formação dos cristãos para a ação social, política, econômica e cultural” (DELGADO, 2007, p. 115).

11 Não localizamos dados sobre esse tipo de envolvimento entre a vítima e o algoz na historiografia brasileira. Em relação à ditadura argentina, no entanto, há duas publicações que abordam o assunto (CALVEIRO, 2013; WORNAT; LEWIN, 2014). Note-se que, em uma delas, Pilar Calveiro destacou que a tortura configurava a sustentação de uma máquina repressora que controlava a vida e a morte de cada preso político, quebrando o indivíduo física e psicologicamente, mediante uma violência intensiva. Em tal sistema ocorriam práticas de todo tipo, configurando uma completa desumanização, inclusive havendo práticas perversas em que torturadores forçavam as vítimas a jogarem baralho com eles ou as levavam para jantar externamente em restaurantes, como se nada tivesse se passado. Em tal contexto de violência exacerbada, sobreviver, segundo a autora, colocava a vítima em situação de suspeição: como se tivesse colaborado com a ditadura ou se envolvido com o algoz (CALVEIRO, 2013, p. 73-77).

${ }^{12}$ Fábio Uchoa assinala que esse filme de Candeias subverte as comédias eróticas do período, ao apresentar elementos anti-machistas. De acordo com ele, isso é revelado pela encenação da impotência sexual, que configurava castração (UCHOA, 2013, p, 102).

${ }^{13}$ Sobre o tema da repressão às religiosas no Brasil, durante a ditadura civil-militar, Natália Dutra, bolsista PIVIC de História, da Universidade Federal de Goiás, está completando o levantamento, já tendo localizado alguns nomes. 